\title{
Nutritional Requirements for the Improvement of Growth and Sporulation of Several Strains of Monascus purpureus on Solid State Cultivation
}

\author{
Zahra Ajdari, ${ }^{1,2}$ Afshin Ebrahimpour, ${ }^{3}$ Musaalbakri Abdul Manan, ${ }^{4}$ \\ Muhajir Hamid, ${ }^{5}$ Rosfarizan Mohamad, ${ }^{2}$ and Arbakariya B. Ariff ${ }^{2}$ \\ ${ }^{1}$ Department of Marine Biotechnology, Iranian Fisheries Research Organization, No. 297, West Fatemi Avenue, \\ P.O. Box 14155-6116, 1411816616 Tehran, Iran \\ ${ }^{2}$ Department of Bioprocess Technology, Faculty of Biotechnology and Biomolecular Science, Universiti Putra Malaysia, \\ 43400 Serdang, Selangor, Malaysia \\ ${ }^{3}$ Department of Food Science, Faculty of Food Science and Technology, Universiti Putra Malaysia, \\ Selangor, 43400 Serdang, Malaysia \\ ${ }^{4}$ Biotechnology Research Center, Malaysian Agricultural Research and Development Institute, P.O. Box 12301, \\ 50774 Kuala Lumpur, Malaysia \\ ${ }^{5}$ Department of Microbiology, Faculty of Biotechnology and Biomolecular Science, Universiti Putra Malaysia, \\ Selangor, 43400 Serdang, Malaysia
}

Correspondence should be addressed to Arbakariya B. Ariff, arbarif@biotech.upm.edu.my

Received 12 July 2011; Revised 15 September 2011; Accepted 16 September 2011

Academic Editor: J. Birchler

Copyright (c) 2011 Zahra Ajdari et al. This is an open access article distributed under the Creative Commons Attribution License, which permits unrestricted use, distribution, and reproduction in any medium, provided the original work is properly cited.

\begin{abstract}
This paper describes the nutritional requirements for the improvement of growth and sporulation of several strains of Monascus purpureus on solid state cultivation. The findings revealed that glucose enhanced growth of all M. purpureus strains tested but inhibited the sporulation rate. On the other hand, sucrose induced sporulation but inhibited production of cell mass. A combination of glucose and sucrose greatly enhanced sporulation and cell mass production of M. purpureus. Although growth and sporulation rate were related to the ratio of carbon to nitrogen $(\mathrm{C} / \mathrm{N}$ ratio), the types and concentrations of carbon and nitrogen sources also greatly influenced the growth kinetics. Among the media tested, Hiroi-PDA medium was the most preferred medium for all $M$. purpureus strains tested for the enhancement of radial growth rate, sporulation, and cell production. Hence, Hiroi-PDA could be suggested as the generic basal medium for the cultivation of M. purpureus. However, individual medium optimization is required for significant enhancement in growth and sporulation of each strain of M. purpureus.
\end{abstract}

\section{Introduction}

The most important characteristic of the genus Monascus, which belongs to the Ascomycetes class and the Monascaceae family, is the ability to produce secondary metabolites of polyketide structure $[1,2]$. This mould has been cultured on rice and used as a part of Chinese food for thousands of years and is generally known as red mould rice. The most famous secondary metabolites, which have been purified and identified from these fungi, include monacolins, GABA, dimerumic acid with medical effects, pigments as natural colorants, and citrinin as an antibacterial agent [3-5].
Many filamentous Ascomycetes spend most of their life cycles as haploids, and many forms of asexual spores (conidia) serve as vegetative propagules or male (fertilizing) parents in sexual crosses. Asexual sporulation is a common reproductive mode for Monascus species [6]. Under favourable environmental conditions, each conidium can produce a young mycelium. The size and shape of spores and colonies of filamentous fungi are the important factors in fungal identification. In fungal fermentation, inoculation could be performed using either a culture in the form of vegetative cells or spores suspension. Improvement of radial growth rate would be considered when vegetative cells need 
to be used as an inoculum in fermentation process. The inoculum in the form of spores has many advantages in comparison to vegetative cells, such as ease in handling, high viability, and stability for a long period of storage, maintenance, and preservation. However, as the sporulation rate of Monascus spp is low due to its asc feature, the inoculum in the form of vegetative cell is widely used in fermentation employing Monascus spp. Sporulation rate of Monascus spp may be improved by the optimization of medium composition. Since Monascus spp are nontoxic fungi, the Monascus fermented product can be consumed directly as food or nutraceutical supplements with multiple therapeutic benefits. For the development of industrial process, nutritional requirements for the enhancement of growth and sporulation of Monascus spp will be identified. The preferred growth characteristics of Monascus spp for high-level production of the desired secondary metabolites will also be identified.

Generally, the growth media for fungi contain carbon (C) and nitrogen $(\mathrm{N})$ sources, and most fungi require several specific elements for growth and reproduction [7-9]. In addition, various types of $\mathrm{C}$ and $\mathrm{N}$ sources could be utilised by fungi due to their ability in secreting various enzymes for the degradation of the polymers into small molecules [10]. This means that the type and concentration of $\mathrm{C}$ and $\mathrm{N}$ sources, $\mathrm{C} / \mathrm{N}$ ratio, and vitamins are the important factors in medium formulation for the enhancement of fungal growth and sporulation. Although potato dextrose agar (PDA) and malt extract agar (MEA) are generally known as the most common media for growth and sporulation of fungi [4], they are only suitable for laboratory scale and might not be economic at large-scale production. Rani et al. [11] claimed that the Abrus sucrose agar was the preferred medium for growth of fungi as compared to Czapek's Dox agar and PDA. Furthermore, the importance of $\mathrm{C} / \mathrm{N}$ ratio on growth of fungi and their ability to sporulate have been reported by several researchers $[7,12,13]$. For instance, Lee et al. [14] revealed that low concentrations of mineral supplements $\left(\mathrm{Zn}^{2+}, \mathrm{Mn}^{2+}, \mathrm{Cu}^{2+}\right.$, and $\left.\mathrm{Fe}^{2+}\right)$ were essential for growth of Monascus spp., whereas high concentrations caused toxicity.

Since fungi can be adapted to grow on solid substrates, the mechanisms involved in the control and regulation of mycelial growth are better studied on solid media than in submerged cultures. Information on the nutritional requirements for the enhancement of growth and sporulation rate of Monascus spp on solid state cultivation is lacking. Thus, the main objective of this study was to investigate the effect of medium composition on growth and sporulation rate of several Monascus purpureus strains on solid state cultivation. The information generated would be useful for the formulation of industrial media for large-scale cultivation of these fungal strains, which have potential in various industrial applications such as the production of Monascus fermented products for use as health food and pharmaceutics.

\section{Materials and Methods}

2.1. Materials. Yeast extract, malt extract, casamino acid, agar, standard czapek medium, MEA, PDA, and peptone were purchased from Difco (Detroit, MI, USA). Other chemicals used in this study were purchased from Merck KGaA (Darmstadt, Germany).

2.2. Microorganisms. Seven Monascus purpureus strains were used in this study. Three M. purpureus strains (DSM1379, DSM1604, and DSM1603) were obtained from the German collection of microorganisms and cell cultures (DSMZ), while the other four M. purpureus strains (FTC5391, FTC5400, FTC5354, and FTC5357) were isolated from local sources and maintained at the culture collection in Malaysian Agricultural Research and Development Institute (MARDI). The strains were conserved by routine inoculation and incubation on PDA at $30^{\circ} \mathrm{C}$ for 7 days, followed by storage at $4^{\circ} \mathrm{C}$, and subcultured monthly.

2.3. Growth and Sporulation Experiments. Small pieces of vegetative cells $\left(2 \mathrm{~mm}^{2}\right)$ obtained from the 7-day-old PDA slant were cited in the centre of Petri dishes containing different agar media (Table 1). The spores were harvested after 12 days of inoculation at $30^{\circ} \mathrm{C}$ using sterile saline water containing $2 \%(\mathrm{v} / \mathrm{v})$ Tween 80 . All the experiments were performed in triplicate.

2.4. Analytical Procedures. Growth of M. purpureus strains was estimated by the determination of cell dry weight and the radial growth. For the determination of dry cell weight, the whole agar of the cultivation plate was mixed with $100 \mathrm{~mL}$ distilled water and boiled to dissolve the agar. The agar solution containing the fungal biomass was filtered through the dry Whatman filter paper Number 5 , and the filter paper with the retained fungal cells was then dried in an oven at $90^{\circ} \mathrm{C}$ for $24 \mathrm{~h}$ until a constant dry weight was attained. Radial growth was estimated by measuring the radius of each colony with a ruler from the centre of the Petri dish along two perpendicular axes (four measurements per dish) at the intervals of $48 \mathrm{~h}$. The number of spore was counted using the haemocytometer.

2.5. Statistical Analysis. The differences in mean values among different strains and media were expressed as mean \pm SD. One-way ANOVAs (analysis of variances), LSD (least square differences) in post hoc tests $(P$ value $<0.05)$, and Bivariate correlation were used to test the differences in growth and sporulation rate among the different strains on different media using the PASW statistical software (version 18).

\section{Results}

3.1. Effect of Medium Composition on Radial Growth Rate. The effect of medium composition on growth (radial growth and cell mass production) and sporulation of different strains of $M$. purpureus in various media after 12 days of incubation are summarized in Table 2. The radial growth of the seven strains of $M$. purpureus on various media after 12 days of incubation is shown in Figure 1. For all strains, the radial growth rate was significantly increased in cultivation 
TABLE 1: Medium formulations tested in this study for the improvement of growth and sporulation of various strains of M. purpureus.

\begin{tabular}{|c|c|}
\hline $\begin{array}{l}\text { Hiroi (sucrose medium) } \\
\text { [15] }\end{array}$ & $\begin{array}{l}\text { Sucrose }(100 \mathrm{~g} / \mathrm{L}) \text {, yeast extract }(3 \mathrm{~g} / \mathrm{L}) \text {, casamino acid }(5 \mathrm{~g} / \mathrm{L}), \mathrm{NaNO}_{3}(2 \mathrm{~g} / \mathrm{L}) \text {, } \\
\mathrm{KH}_{2} \mathrm{PO}_{4}(1 \mathrm{~g} / \mathrm{L}), \mathrm{MgSO}_{4} \cdot 7 \mathrm{H}_{2} \mathrm{O}(0.5 \mathrm{~g} / \mathrm{L}), \mathrm{KCl}(0.5 \mathrm{~g} / \mathrm{L}), \mathrm{FeSO}_{4}(0.01 \mathrm{~g} / \mathrm{L}) \text {, agar } \\
(15 \mathrm{~g} / \mathrm{L})\end{array}$ \\
\hline Hiroi-PDA & $\begin{array}{l}\text { Sucrose }(100 \mathrm{~g} / \mathrm{L}) \text {, yeast extract }(3 \mathrm{~g} / \mathrm{L}) \text {, casamino acid }(5 \mathrm{~g} / \mathrm{L}), \mathrm{NaNO}_{3}(2 \mathrm{~g} / \mathrm{L}) \text {, } \\
\mathrm{KH}_{2} \mathrm{PO}_{4}(1 \mathrm{~g} / \mathrm{L}), \mathrm{MgSO}_{4} \cdot 7 \mathrm{H}_{2} \mathrm{O}(0.5 \mathrm{~g} / \mathrm{L}), \mathrm{KCl}(0.5 \mathrm{~g} / \mathrm{L}), \mathrm{FeSO}_{4}(0.01 \mathrm{~g} / \mathrm{L}) \text {, potato } \\
\text { starch }(4 \mathrm{~g} / \mathrm{L}) \text {, dextrose }(20 \mathrm{~g} / \mathrm{L}) \text {, agar }(15 \mathrm{~g} / \mathrm{L})\end{array}$ \\
\hline PDA & Potato starch $(4 \mathrm{~g} / \mathrm{L})$, dextrose $(20 \mathrm{~g} / \mathrm{L})$, agar $(15 \mathrm{~g} / \mathrm{L})$ \\
\hline Power medium (PM) [16] & $\begin{array}{l}\text { Lactose }(30 \mathrm{~g} / \mathrm{L}) \text {, bacto pepton }(5 \mathrm{~g} / \mathrm{L}) \text {, corn steep solids }(0.5 \mathrm{~g} / \mathrm{L}), \mathrm{NaCl}(4 \mathrm{~g} / \mathrm{L}), \\
\mathrm{CuSO}_{4} \cdot 7 \mathrm{H}_{2} \mathrm{O}(0.001 \mathrm{~g} / \mathrm{L}), \mathrm{FeCl}_{3} \cdot 6 \mathrm{H}_{2} \mathrm{O}(0.003 \mathrm{~g} / \mathrm{L}), \mathrm{KH}_{2} \mathrm{PO}_{4}(0.006 \mathrm{~g} / \mathrm{L}), \mathrm{MgSO}_{4} \cdot 7 \\
\mathrm{H}_{2} \mathrm{O}(0.05 \mathrm{~g} / \mathrm{L}) \text {, agar }(15 \mathrm{~g} / \mathrm{L})\end{array}$ \\
\hline Improved medium (IM) & $\begin{array}{l}\text { Dextrose }(8 \mathrm{~g} / \mathrm{L}), \mathrm{MgSO}_{4} \cdot 7 \mathrm{H}_{2} \mathrm{O}(2.5 \mathrm{~g} / \mathrm{L}), \mathrm{KH}_{2} \mathrm{PO}_{4}(2.7 \mathrm{~g} / \mathrm{L}) \text {, peptone }(2.4 \mathrm{~g} / \mathrm{L}) \text {, } \\
\text { yeast extract }(2 \mathrm{~g} / \mathrm{L}), \operatorname{agar}(15 \mathrm{~g} / \mathrm{L})\end{array}$ \\
\hline MEA [17] & Malt extract $(20 \mathrm{~g} / \mathrm{L})$, glucose $(20 \mathrm{~g} / \mathrm{L})$, peptone $(10 \mathrm{~g} / \mathrm{L})$, agar $(15 \mathrm{~g} / \mathrm{L})$ \\
\hline
\end{tabular}

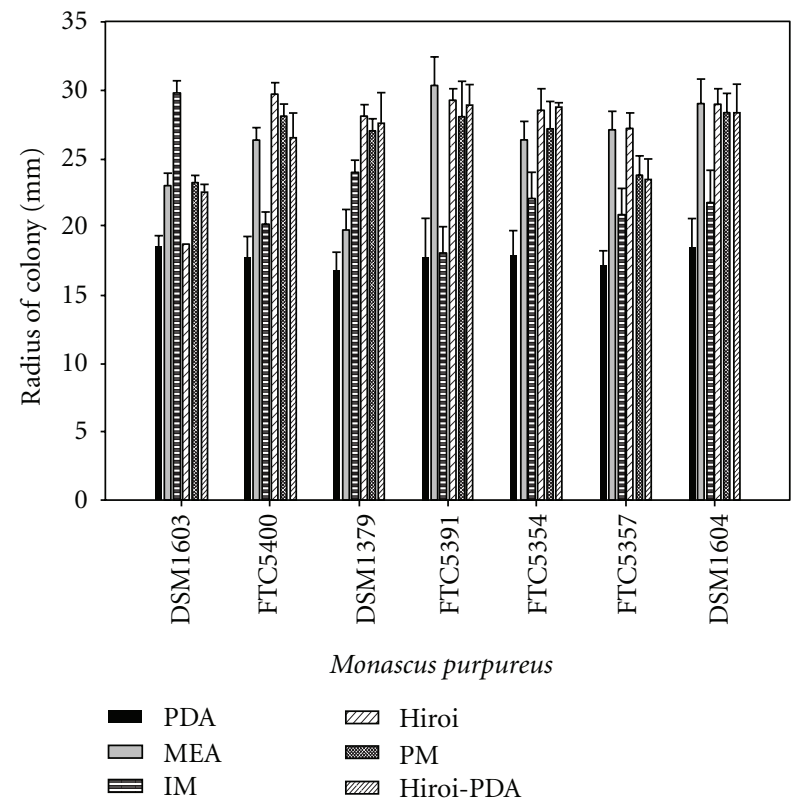

FIGURE 1: Comparison of colony mean radius for different strains of Monascus spp after 12 days of cultivation on different media. Data are average of three determinations (mean $\pm \mathrm{SD}$ ).

using a mixture of Hiroi and PDA media. The radial growth rate on PDA and improved medium (IM) were significantly lower than the other media, whereas the radial growth rate on Hiroi was the highest for all strains, except for the DSM1603 strain, which had the highest radial growth rate on IM. One-way ANOVA test showed significant differences of radial growth rate among the different strains on each medium, as follows: Hiroi $(F=29.22$ and $P$ value $=0.00)$, $\operatorname{IM}(F=13.701$ and $P$ value $=0.00)$, MEA $(F=5.368$ and $P$ value $=0.005)$, Hiroi-PDA $(F=3.273$ and $P$ value $=$ $0.032)$, and PM $(F=5.146$ and $P$ value $=0.005)$. However, the radial growth rate on PDA for all strains tested was not significantly different $(F=1.24$ and $P$ value $=0.34)$. LSD of post hoc test indicated that the exact point of differences was between the DSM1603 strain and other strains. The lowest radial growth rate was about $1.67 \mathrm{~mm} /$ day for DSM1379

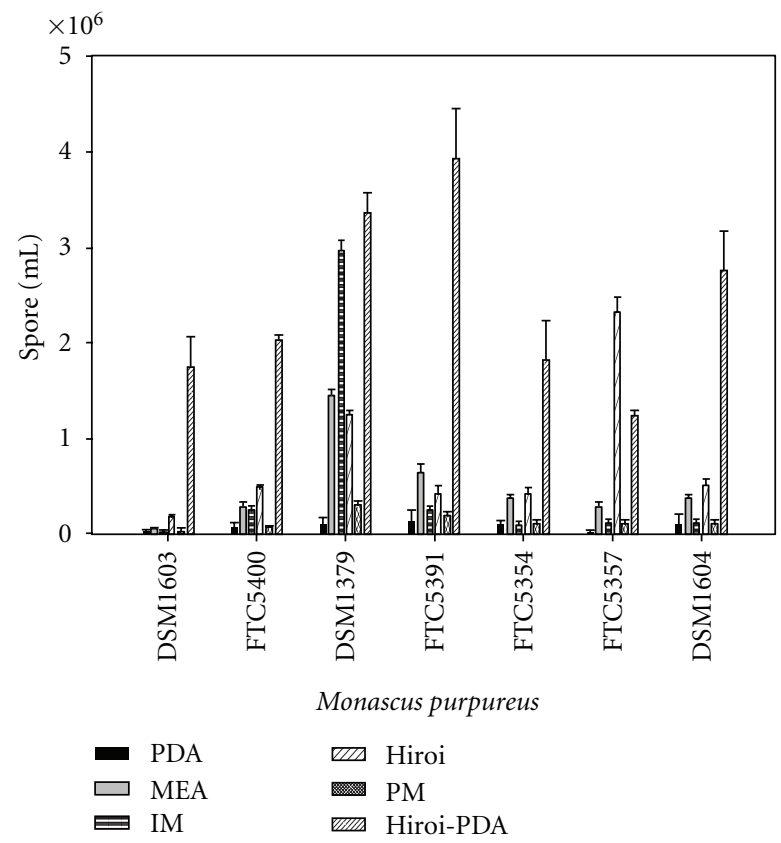

FIGURE 2: Comparison of sporulation among different strains of Monascus spp cultivated on different solid media. Data are average of three determinations (mean $\pm \mathrm{SD}$ ).

on PDA, while the highest was about $3.03 \mathrm{~mm} /$ day for $M$. purpureus FTC5391 on MEA.

3.2. Effect of Medium Composition on Sporulation. Figures 2 and 3 show the effect of medium composition on the sporulation of the seven strains of $M$. purpureus. Sporulation was greatly varied among the different strains on different media tested in this study. The one-way ANOVA test showed that the differences were significant, as follows: Hiroi $(F=$ 285.922 and $P$ value $=0.00)$, IM $(F=1477.602$ and $P$ value $=0.00)$, MEA $(F=194.760$ and $P$ value $=0.005)$, HiroiPDA $(F=27.256$ and $P$ value $=0.00), \operatorname{PM}(F=34.739$ and $P$ value $=0.000)$, and PDA $(F=789.058$ and $P$ value $=0.00$ ). The highest sporulation was induced by Hiroi-PDA medium, while the lowest sporulation was obtained with 


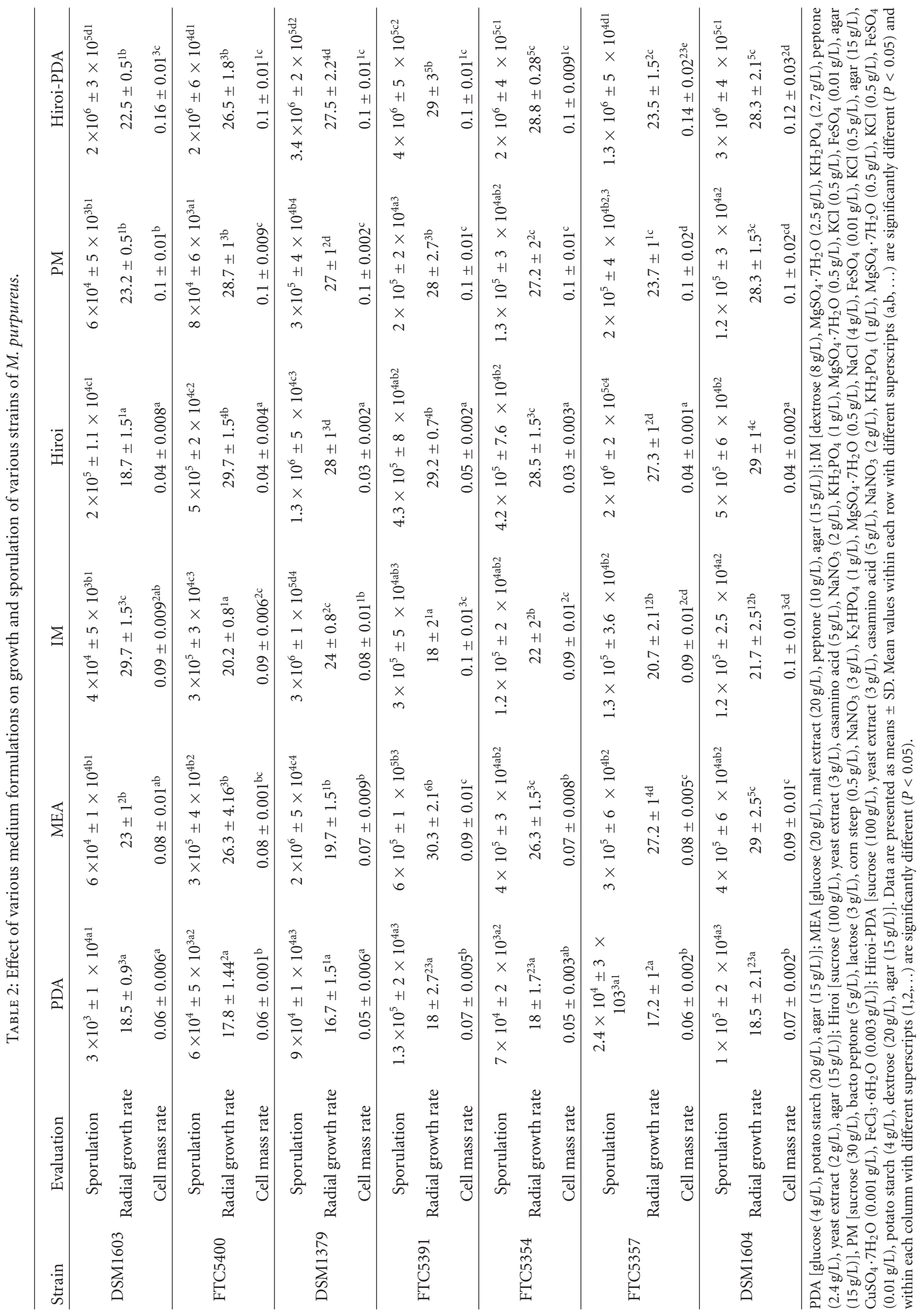




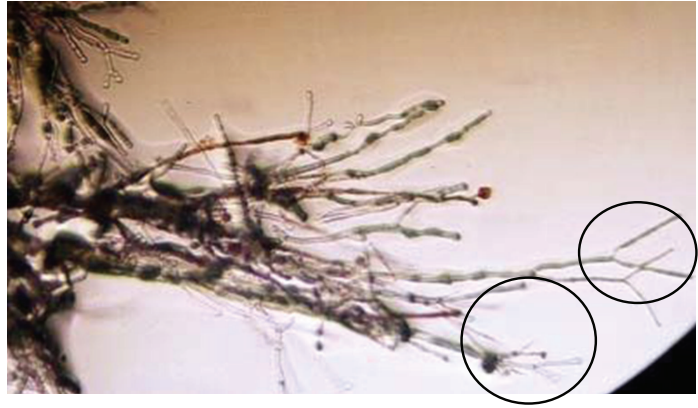

(a)

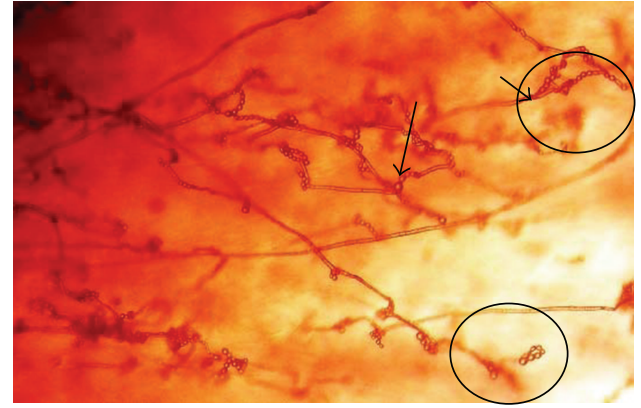

(b)

FIgURE 3: The number of conidia on PDA (a) and Hiroi (b) for DSM1379. Arrows indicated the conidiation (a few conidium on PDA (a) and improvement of conidiation on Hiroi medium (b)).

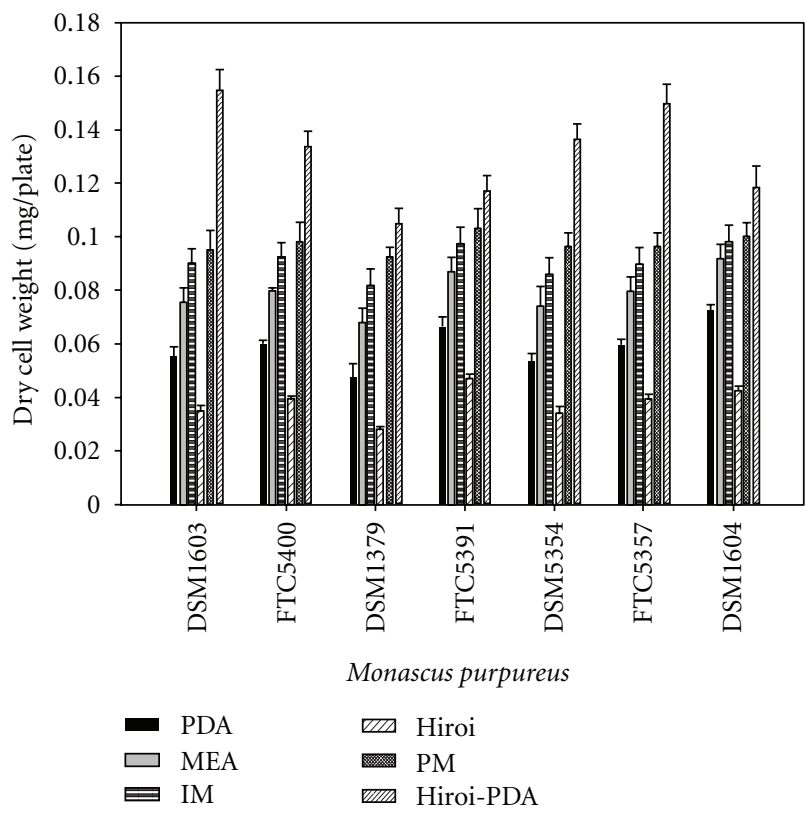

Figure 4: Comparison of cell production by different strains of Monascus spp cultivated on different solid media. Data are average of three determinations (mean $\pm \mathrm{SD}$ ).

the PDA medium. In general, Hiroi and IM media gave the highest spore production for M. purpureus FTC5357 and $M$. purpureus FTC1379.

\subsection{Effect of Medium Composition on Cell Mass Production.} The effect of medium composition on growth of the seven strains of $M$. purpureus, measured as the dry cell weight, is shown in Figure 4. The highest cell production was obtained from the Hiroi-PDA medium, especially for $M$. purpureus DSM 1603, whereas the lowest was obtained from the Hiroi medium. A slight difference in cell production was observed among all strains for growth on MEA, IM, and PM. The results of the one-way ANOVA test among the different strains on different media showed a significant difference only on Hiroi-PDA medium $(F=5.739$ and $P$ value $=$ 0.03). Although Hiroi-PDA medium was the most preferred
TABle 3: Total ingredients of compounds in medium and the percentage of carbon and nitrogen along with $\mathrm{C} / \mathrm{N}$ ratio.

\begin{tabular}{lcccc}
\hline & $\begin{array}{c}\text { Total compounds } \\
(\mathrm{g} / \mathrm{L})\end{array}$ & $\mathrm{C}(\%)$ & $\mathrm{N}(\%)$ & $\mathrm{C} / \mathrm{N}$ \\
\hline Improved medium & 17.6 & 45 & 25 & 1.8 \\
Hiroi & 112.01 & 89.3 & 8.9 & 10.03 \\
MEA & 50 & 60 & 40 & 1.5 \\
Power medium & 73.7 & 82 & 9.5 & 8.6 \\
PDA & 24 & 100 & - & - \\
Hiroi-PDA & 136.4 & 91.2 & 7.4 & 12.3 \\
\hline
\end{tabular}

medium, in general, among all the strains tested, the LSD test (data not shown) showed that the composition of medium for cell production was strain dependent.

3.4. Effect of Medium Formulation on Colony Morphologies. Different medium formulations induced different morphologies of colonies for all the $M$. purpureus strains tested in this study. The morphologies of the M. purpureus strains on Hiroi-PDA were obviously changed in comparison to the other media, especially in the case of DSM1603 (Figure 5).

\subsection{Effect of Carbon to Nitrogen Ratio (C/N) on Radial} Growth Rate, Sporulation, and Cell Production. The C/N ratio of the different media used in this study is elucidated in Table 3, where the range was from 1.5 to 12.3 . The influence of $\mathrm{C} / \mathrm{N}$ ratio on radial growth, sporulation and cell production is shown in Figures 6, 7, and 8. Although significant relation between $\mathrm{C} / \mathrm{N}$ ratio and radial growth is not observed (Figure 6), the effect of $\mathrm{C} / \mathrm{N}$ ratio on radial growth was strain dependent. M. purpureus DSM1603 did not exactly follow the tack of $\mathrm{C} / \mathrm{N}$ ratio on radial growth, where the highest radial growth was obtained at $\mathrm{C} / \mathrm{N}$ ratio of 1.8 while the lowest was obtained at $\mathrm{C} / \mathrm{N}$ ratio of 10.03 . On the contrary, M. purpureus FTC5357 strain had the highest radial growth at $\mathrm{C} / \mathrm{N}$ ratio of 10.03 , while the lowest was observed at $\mathrm{C} / \mathrm{N}$ ratio of 1.8 .

Figures 7 and 8 reveal that the sporulation and cell production were directly related to $\mathrm{C} / \mathrm{N}$ ratio to a certain 


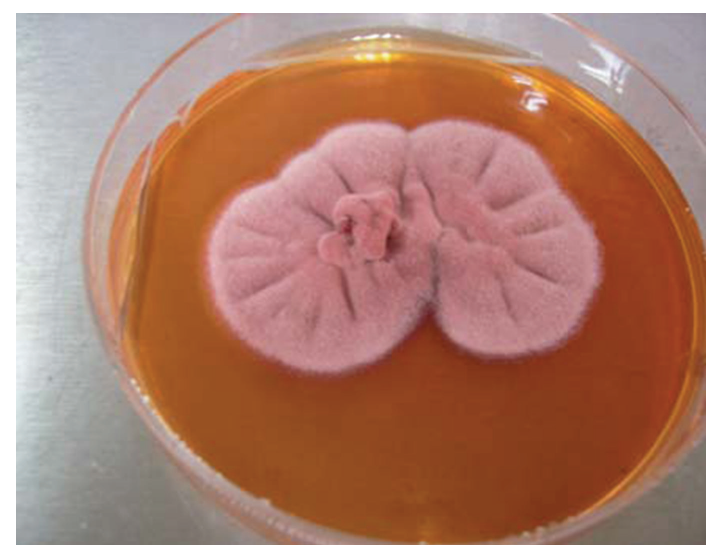

(a)

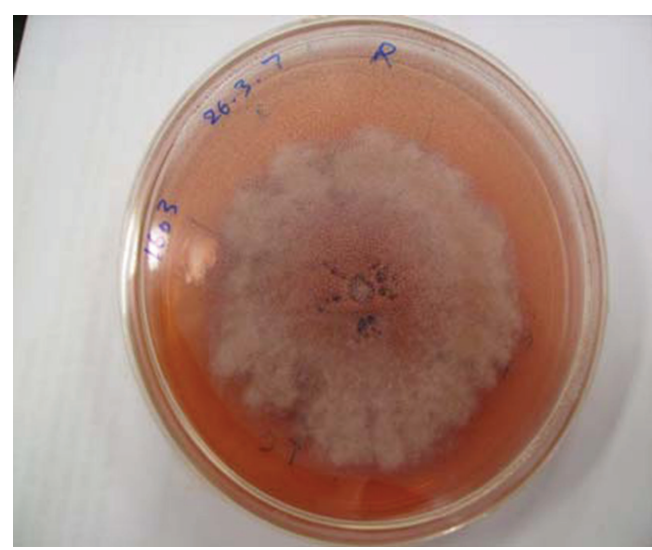

(b)

Figure 5: Different morphologies of M. purpureus DSM 1603 colonies cultivated using two different media, Hiroi-PDA (a) and PDA (b).

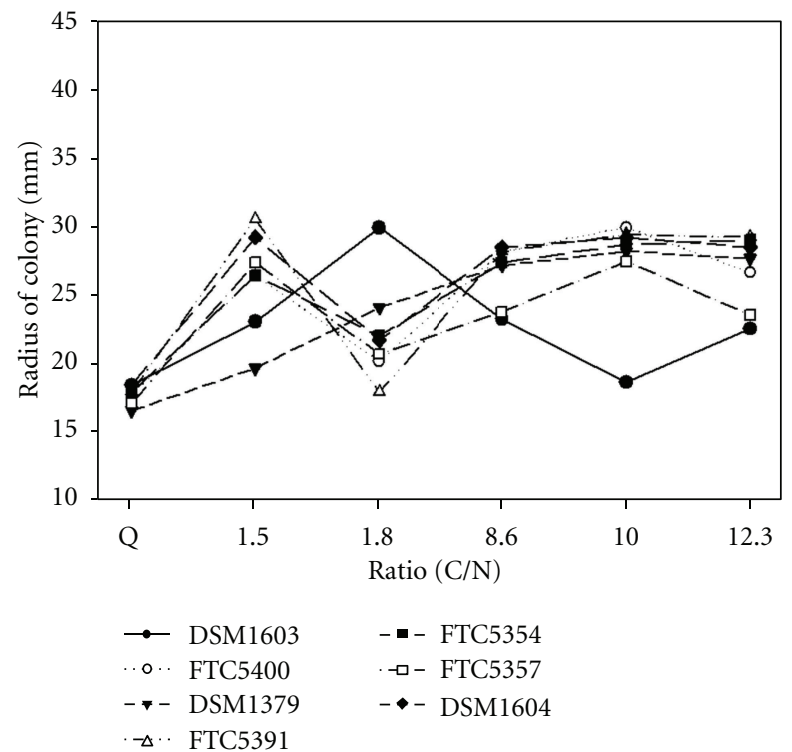

FIGURE 6: Effect of C/N ratio on radial growth of M. purpureus. Q: $\mathrm{C} / \mathrm{N}$ ratio of PDA (potato dextrose agar) medium (PDA does not include nitrogen source), 1.5: $\mathrm{C} / \mathrm{N}$ ratio of MEA (malt extract agar), 1.8: $\mathrm{C} / \mathrm{N}$ ratio of IM (improved medium), 8.6: $\mathrm{C} / \mathrm{N}$ ratio of Hiroi, 10: the $\mathrm{C} / \mathrm{N}$ ratio of $\mathrm{PM}$ (power medium), and 12.3: $\mathrm{C} / \mathrm{N}$ ratio of Hiroi-PDA.

extent. However, the type of $\mathrm{C}$ and $\mathrm{N}$ sources also greatly influenced sporulation and cell production of all the $M$. purpureus strains tested in this study. Figure 6 clearly shows that the effect of $\mathrm{C} / \mathrm{N}$ ratio on sporulation was strain dependent, in which the M. purpureus DSM1379 and M. purpureus FTC5357 strains did not exactly follow the track of $\mathrm{C} / \mathrm{N}$ ratio on sporulation. The sporulation of $M$. purpureus DSM1379 was first increased from the medium without $\mathrm{N}$ source to the medium with $\mathrm{C} / \mathrm{N}$ ratio of 1.8 , and decreased drastically with the increase of $\mathrm{C} / \mathrm{N}$ ratio from 1.8 to 8.6. However, the sporulation was enhanced at higher $\mathrm{C} / \mathrm{N}$ ratio (10.3 to 12.3 ). The highest sporulation of $M$.

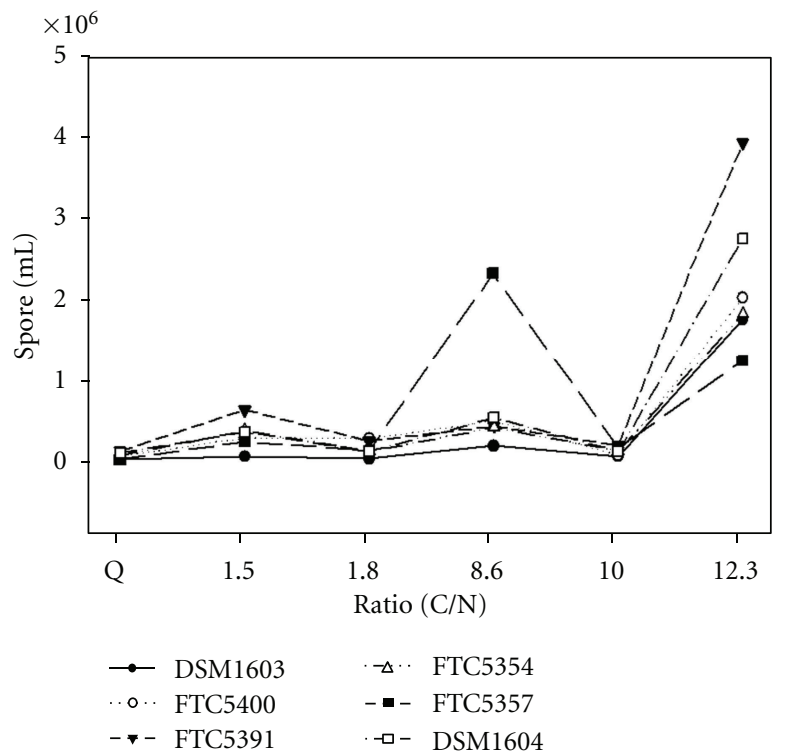

FIGURE 7: Effect of C/N ratio on sporulation of $M$. purpureus. Q: $\mathrm{C} / \mathrm{N}$ ratio of PDA (potato dextrose agar) medium (PDA does not include nitrogen source), 1.5: $\mathrm{C} / \mathrm{N}$ ratio of MEA (malt extract agar), 1.8: $\mathrm{C} / \mathrm{N}$ ratio of IM (improved medium), 8.6: $\mathrm{C} / \mathrm{N}$ ratio of Hiroi, 10: $\mathrm{C} / \mathrm{N}$ ratio of PM (power medium), and 12.3: $\mathrm{C} / \mathrm{N}$ ratio of HiroiPDA.

purpureus FTC5357 was observed in the medium with $\mathrm{C} / \mathrm{N}$ ratio of 10.3. Sporulation was increased drastically with the increase in $\mathrm{C} / \mathrm{N}$ ratio from 8.6 to 10.03 , where inhibition of sporulation was observed at higher $\mathrm{C} / \mathrm{N}$ ratio $(>10.03)$. Figure 7 shows that the cell production of all strains was constantly increased with increasing $\mathrm{C} / \mathrm{N}$ ratio up to 8.6. A slight reduction in cell production was observed at higher $\mathrm{C} / \mathrm{N}$ ratio $(<10.3)$. However, enhancement of cell production was again observed at very high $\mathrm{C} / \mathrm{N}$ ratios $(>12.3)$.

3.6. Correlation between Radial Growth, Sporulation, and Cell Production. Table 4 shows the correlation between radial 
TABLE 4: Correlation between radial growth, cell mass production, and sporulation of $M$. purpureus strains cultivated on different solid media.

\begin{tabular}{lccc}
\hline M. purpureus strain & $\begin{array}{c}\text { Radial growth/sporulation } \\
(\%)\end{array}$ & $\begin{array}{c}\text { Radial growth/cell mass production } \\
(\%)\end{array}$ & $\begin{array}{c}\text { Sporulation/cell mass production } \\
(\%)\end{array}$ \\
\hline DSM1379 & 2.5 & 0 & 0 \\
DSM1604 & 31 & 0 & 72 \\
DSM1603 & 0.5 & 76 & 0 \\
FTC5391 & 80 & 0.4 & 0 \\
FTC5357 & 85 & 0 & 34 \\
FTC5400 & 67 & 0 & 0 \\
\hline
\end{tabular}

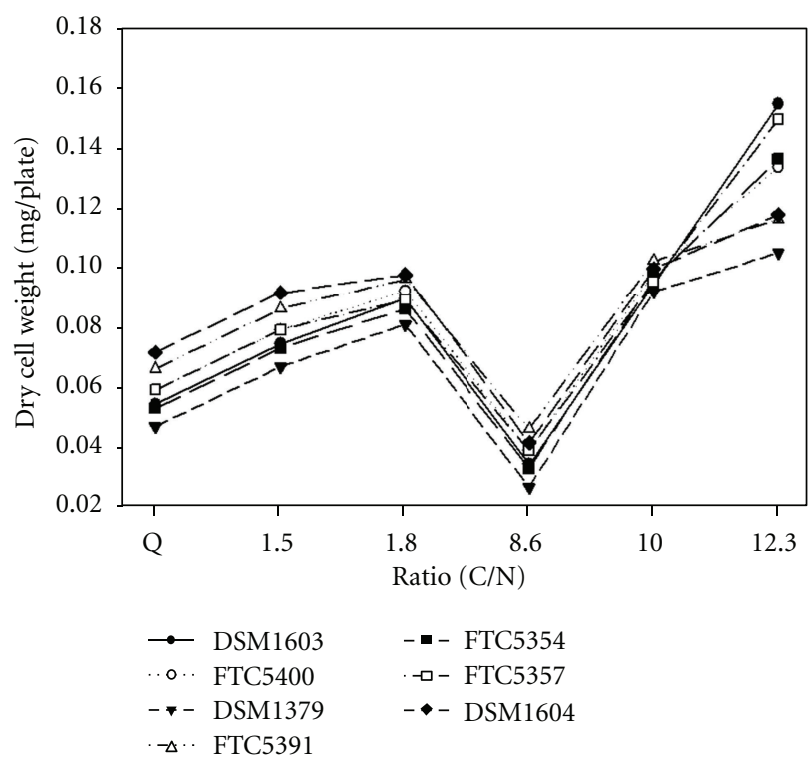

FIGURE 8: Effect of $\mathrm{C} / \mathrm{N}$ ratio on the production of $M$. purpureus cells. Q: C/N ratio of PDA (potato dextrose agar) medium (PDA without nitrogen source), 1.5: $\mathrm{C} / \mathrm{N}$ ratio of MEA (malt extract agar), 1.8: $\mathrm{C} / \mathrm{N}$ ratio of IM (improved medium), 8.6: $\mathrm{C} / \mathrm{N}$ ratio of Hiroi, 10: $\mathrm{C} / \mathrm{N}$ ratio of $\mathrm{PM}$ (power medium), and 12.3: C/N ratio of HiroiPDA.

growth, sporulation, and cell mass production. The results displayed a significant correlation between radial growth and mass production in all strains, while there was no significant correlation between sporulation and cell mass production as well as sporulation and radial growth rate.

\section{Discussion}

Fungal nutritional requirements are important not only for successful cultivation in the laboratory but also for the optimization of industrial fermentation processes [9]. It is well known that the type and concentration of carbon and nitrogen sources as well as $\mathrm{C} / \mathrm{N}$ ratio play important roles on fungal growth and sporulation [7, 18, 19]. Manipulation of the nutritional requirement is the simplest and most effective way to improve the cultivation performance, considering growth, production of the target metabolite, yield, and productivity. Selection of the basal medium is the first step in the optimization of medium. In this study, six media were tested in order to achieve a favourable basal medium for the improvement of growth and sporulation of several M. purpureus strains. Results from this study have demonstrated that the radial growth rate, sporulation, cell mass production, and colony morphology of several strains of $M$. purpureus were greatly influenced by different compositions of solid media. The ability of $M$. purpureus to grow and sporulate was greatly enhanced when a combination of PDA and Hiroi media was used. This means that the interactions of nutrients in both media are required to improve growth and sporulation of $M$. purpureus. Although Hiroi-PDA medium was preferred to enhance sporulation, radial growth, and cell production in cultivation of $M$. purpureus on solid media, significant correlation between these growth parameters for the different strains on different media was not observed. Growth and sporulation of fungi on synthetic media are usually related to the species and medium composition [20]. Comparison between PDA (a nonfavourable medium for radial growth rate) and Hiroi (a favourable medium for radial growth rate) with other media indicates that the variation in radial growth rate was related to the different carbon sources used in the different media. In general, radial growth of $M$. purpureus was enhanced when sucrose was present in the medium as a carbon source. In radial growth, the rates of branching and tip growth were related to the cytoplasmic volume [9], which may be stimulated due to the presence of sucrose as observed in this study. The ability to utilize nitrate, ammonium, or organic nitrogen sources determines the extent of vegetative growth and, consequently, the reproduction capacity of the fungus. There is little evidence that sporulation requires an element that is nonessential for growth [8]. Lee et al. [14] reported that inorganic ions and growth factors were required to stimulate growth of $M$. purpureus.

The effects of nutritional factors on fungi sporulation have been studied by several researchers. Ammonium sulphate and sodium nitrate inhibited the conidiation of Penicillium camemberti in solid medium, while the presence of potassium nitrate induced the conidiation [21]. Similar results have also been reported for Aspergillus spp [22, 23] and Monascus spp [24]. Notably, the favourable media (Hiroi-PDA and Hiroi) for the enhancement of sporulation 
of all M. purpureus strains tested in this study contained nitrate and no ammonium. Sucrose has been reported as the inhibitor to $M$. purpureus cell production [17]. On the other hand, glucose was identified as the inducer for the production of $M$. purpureus cells $[25,26]$. It is well known that bacterial and fungal spores are formed as a response to unfavourable conditions. Nitrogen starvation and calcium supply induce sporulation at higher rate than carbon starvation [21]. The Hiroi-PDA medium employed in this study to enhance the sporulation of $M$. purpureus contained high amount of sugar (glucose and sucrose) and low amount of nitrogen sources. In contrast, Rajderkar [8] claimed that low sugar concentration gave higher sporulation rate than high sugar concentration. The ability of fungi to sporulate was related to a sophisticated system of positive and negative gene regulations, which were affected by the environmental and nutritional factors. Temporal and spatial regulations of gene expression, cell specialization, and intercellular communication may affect the conidiation in fungal system $[6,27]$. The genetic mechanisms controlling the conidiation process have been well described in two Ascomycetes systems, Aspergillus nidulans and Neurospora crassa [27]. Only a few genetic mechanisms concerned with Monascus spp have been reported [6]. In Monascus spp cell systems, formation of either asexual or sexual spores appears to be an efficient method of cell proliferation. Although the general mechanisms managing the sporulation in fungi are similar, definitely, there are some important differences. Variation in the ability of different Monascus strains in the same species to sporulate with different medium compositions is related to the genetic differences in detail. However, further study is deemed necessary to identify the relationship between the genetic mechanisms controlling the sporulation and nutritional requirements.

The results from this study also revealed that the effect of $\mathrm{C} / \mathrm{N}$ ratio on radial growth, sporulation, and cell production during the cultivation of $M$. purpureus on solid media was strain dependent. Sporulation was increased with increasing $\mathrm{C} / \mathrm{N}$ ratio up to certain levels dependent on the strains, where a drastic reduction in sporulation was occurred. From the correlation between growth rate and spore production, it was revealed that the preferred medium for growth rate may not be necessarily suitable to enhance spore production. For example, growth of M. purpureus FTC5391 was enhanced on cultivation using Hiroi, MEA, Power, and Hiroi-PDA media, but spore production was only enhanced on cultivation using Hiroi-PDA medium. It is very obvious that specific medium formulation was required for the enhancement of growth and sporulation of the specific M. purpureus strain. In other words, a generic medium formulation could not be applied for all $M$. purpureus strains. The findings from this study are important information for the development of the fermentation process for the production of Monascus fermented products, which have found many applications as health foods and pharmaceutics. This means that the individual medium optimization should be carried out for M. purpureus strain to be employed in the process. However, Hiroi-PDA could be used as a generic basal medium for the cultivation of $M$. purpureus strains.

\section{Conclusion}

Growth parameters (radial growth, sporulation, and cell mass production) of several M. purpureus strains cultivated on solid medium were greatly influenced by medium composition and was found to be strain dependent. The use of polysaccharide, disaccharide, and monosaccharide as carbon sources along with nitrogen source was contributory factors implicated in the onset of radial growth and conidiation as well as enhancement in cell production and variation in colony morphology. Sucrose induced sporulation and inhibited production of cell mass. Glucose alone did not induce sporulation. A combination of glucose and sucrose greatly enhanced sporulation, and cell mass production of M. purpureus. Among the media tested, Hiroi-PDA medium was the most favourable medium for the enhancement of radial growth, sporulation and cell mass production of all M. purpureus strains tested in this study. Hence, Hiroi-PDA could be suggested as the generic basal medium for the cultivation of $M$. purpureus, either for the improvement of secondary metabolites production or for the production of Monascus fermented products.

\section{Acknowledgments}

The financial supports by Universiti Putra Malaysia and Malaysian Agricultural Research and Development Institute (MARDI) are gratefully acknowledged.

\section{References}

[1] P. Juzlova, L. Martinkova, and V. Kren, "Secondary metabolites of the fungus Monascus: a review," Journal of Industrial Microbiology, vol. 16, no. 3, pp. 163-170, 1996.

[2] O. Edogrul and S. Azirak, "Review of the studies on the red yeast rice (Monascus purpureus)," Turkish Electronic Journal Of Biotechnology, vol. 2, pp. 37-49, 2004.

[3] Y. C. Su, J. J. Wang, T. T. Lin, and T. M. Pan, "Production of the secondary metabolites $\gamma$-aminobutyric acid and monacolin K by Monascus," Journal of Industrial Microbiology and Biotechnology, vol. 30, no. 1, pp. 41-46, 2003.

[4] J. C. Carvalho et al., "Biopigments from Monascus: strains selection, citrinin production and color stability," Brazilian Achives of Biology and Technology, vol. 48, pp. 885-894, 2005.

[5] Y. L. Lin, T. H. Wang, M. H. Lee, and N. W. Su, "Biologically active components and nutraceuticals in the Monascusfermented rice: a review," Applied Microbiology and Biotechnology, vol. 77, no. 5, pp. 965-973, 2008.

[6] J. H. Suh and C. S. Shin, "Analysis of the morphologic changes of Monascus sp. J101 cells cocultured with Saccharomyces cerevisiae," FEMS Microbiology Letters, vol. 193, no. 1, pp. 143147, 2000.

[7] L. Gao, M. H. Sun, X. Z. Liu, and Y. S. Che, "Effects of carbon concentration and carbon to nitrogen ratio on the growth and sporulation of several biocontrol fungi," Mycological Research, vol. 111, no. 1, pp. 87-92, 2007.

[8] N. R. Rajderkar, "Certain chemical requirements for growth and sporulation of alternaria species," Mycopathologia et Mycologia Applicata, vol. 30, no. 2, pp. 172-176, 1966. 
[9] G. M. Walker and N. A. White, "Introduction to fungal physiology," in Fungi: Biology and Application, K. Kavanagh, Ed., Wiley, 2005.

[10] C. L. Lee, H. K. Hung, J. J. Wang, and T. M. Pan, "Improving the ratio of monacolin $\mathrm{K}$ to citrinin production of Monascus purpureas NTU 568 under dioscorea medium through the mediation of $\mathrm{pH}$ value and ethanol addition," Journal of $\mathrm{Ag}$ ricultural and Food Chemistry, vol. 55, no. 16, pp. 6493-6502, 2007.

[11] I. Rani, M. Sohail, S. Akhund, and H. Abro, "Abrus sucrose agar a new medium for the growth of fungi," Pakistan Journal of Botany, vol. 39, no. 5, pp. 1883-1885, 2007.

[12] J. Z. Wu, P. C. K. Cheung, K. H. Wong, and N. L. Huang, "Studies on submerged fermentation of Pleurotus tuberregium (Fr.) Singer-part 1: physical and chemical factors affecting the rate of mycelial growth and bioconversion efficiency," Food Chemistry, vol. 81, no. 3, pp. 389-393, 2003.

[13] J. Z. Wu, P. C. K. Cheung, K. H. Wong, and N. L. Huang, "Studies on submerged fermentation of Pleurotus tuber-regium (Fr.) Singer. Part 2: effect of carbon-to-nitrogen ratio of the culture medium on the content and composition of the mycelial dietary fibre," Food Chemistry, vol. 85, no. 1, pp. 101105,2004

[14] B. K. Lee, H. Y. Piao, and W. J. Chung, "Production of red pigments by Monascus purpureus in submerged culture," Biotechnology and Bioprocess Engineering, vol. 7, pp. 21-25, 2002.

[15] C. S. Shin, H. J. Kim, M. J. Kim, and J. Y. Ju, "Morphological change and enhanced pigment production of Monascus when cocultured with Saccharomyces cerevisiae or Aspergillus oryzae," Biotechnology and Bioengineering, vol. 59, no. 5, pp. 576-581, 1998.

[16] F. Fierro, E. Montenegro, S. Gutièrrez, and J. F. Martín, "Mutants blocked in penicillin biosynthesis show a deletion of the entire penicillin gene cluster at a specific site within a conserved hexanucleotide sequence," Applied Microbiology and Biotechnology, vol. 44, no. 5, pp. 597-604, 1996.

[17] Y. Y. Tseng, M. T. Chen, and C. F. Lin, "Growth, pigment production and protease activity of Monascus purpureus as affected by salt, sodium nitrite, polyphosphate and various sugars," Journal of Applied Microbiology, vol. 88, no. 1, pp. 3137, 2000.

[18] M. A. Jackson and D. A. Schisler, "The composition and attributes of Colletotrichum truncatum spores are altered by the nutritional environment," Applied and Environmental Microbiology, vol. 58, no. 7, pp. 2260-2265, 1992.

[19] M. A. Jackson and P. J. Slininger, "Submerged culture conidial germination and conidiation of the bioherbicide Colletotrichum truncatum are influenced by the amino acid composition of the medium," Journal of Industrial Microbiology, vol. 12, no. 6, pp. 417-422, 1993.

[20] J. P. Latge and J. J. Sanglier, "Optimisation de la croissance et de la sporulation de Conidiobolus obscurus en milieu defini," Canadian Journal of Botany, vol. 63, pp. 68-85, 1985.

[21] I. Krasniewski, P. Molimard, G. Feron et al., "Impact of solid medium composition on the conidiation in Penicillium camemberti," Process Biochemistry, vol. 41, no. 6, pp. 1318 $1324,2006$.

[22] I. Skromne, O. Sanchez, and J. Aguirre, "Starvation stress modulates the expression of the Aspergillus nidulans brlA regulatory gene," Microbiology, vol. 141, no. 1, pp. 21-28, 1995.

[23] A. M. Calvo, R. A. Wilson, J. W. Bok, and N. P. Keller, "Relationship between secondary metabolism and fungal development," Microbiology and Molecular Biology Reviews, vol. 66, no. 3, pp. 447-459, 2002.

[24] M. Carels and D. Shepherd, "The effect of different nitrogen sources on pigment production and sporulation of Monascus species in submerged, shaken culture," Canadian Journal of Microbiology, vol. 23, no. 10, pp. 1360-1372, 1977.

[25] T. F. Lin and A. L. Demain, "Effect of nutrition of Monascus sp. on formation of red pigments," Applied Microbiology and Biotechnology, vol. 36, no. 1, pp. 70-75, 1991.

[26] T. F. Lin and A. L. Demain, "Resting cell studies on formation of water-soluble red pigments by Monascus sp," Journal of Indian Microbiology, vol. 162, pp. 114-119, 1993.

[27] T. H. Adams, J. K. Wieser, and J. H. Yu, "Asexual sporulation in Aspergillus nidulans," Microbiology and Molecular Biology Reviews, vol. 62, no. 1, pp. 35-54, 1998. 

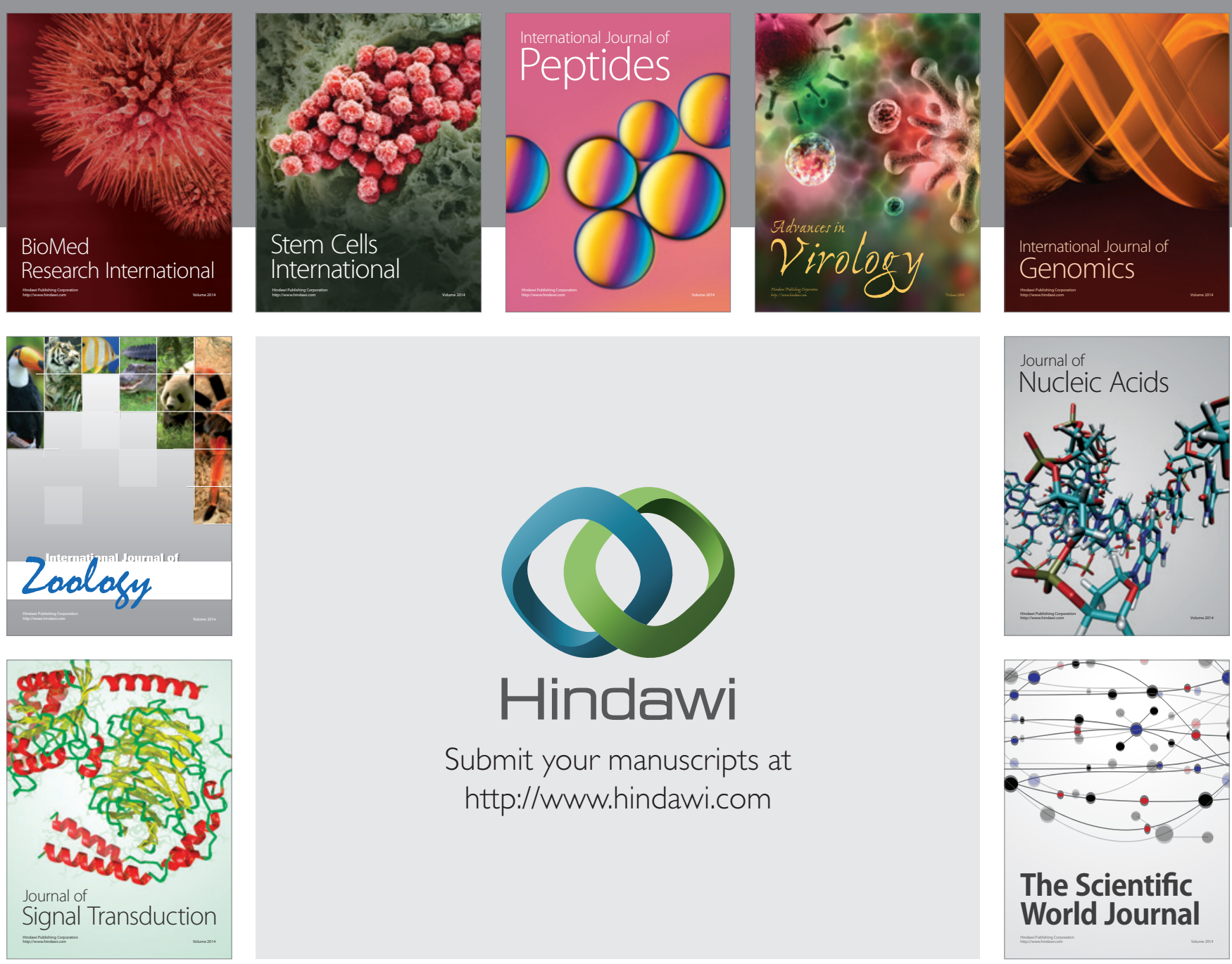

Submit your manuscripts at

http://www.hindawi.com
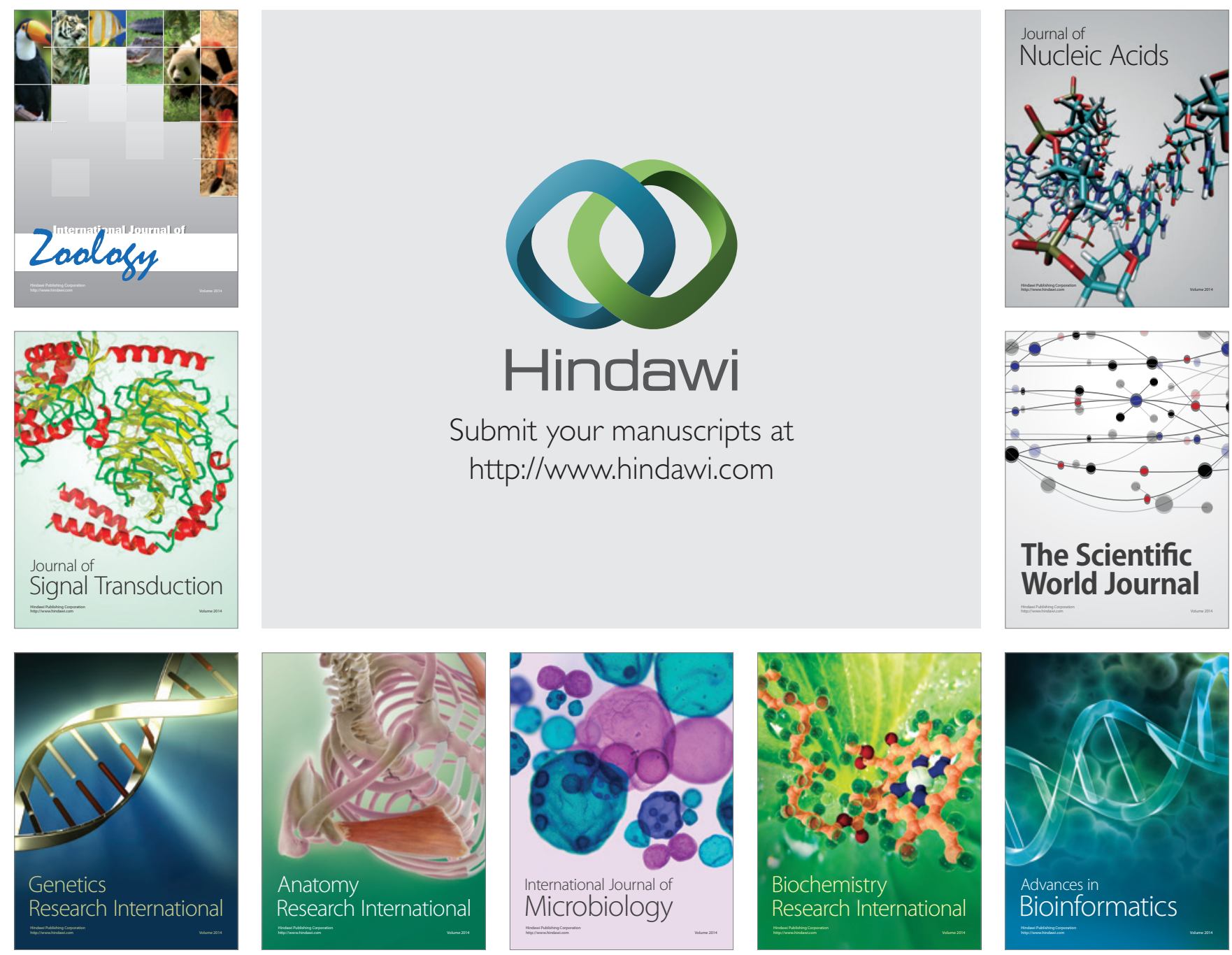

The Scientific World Journal
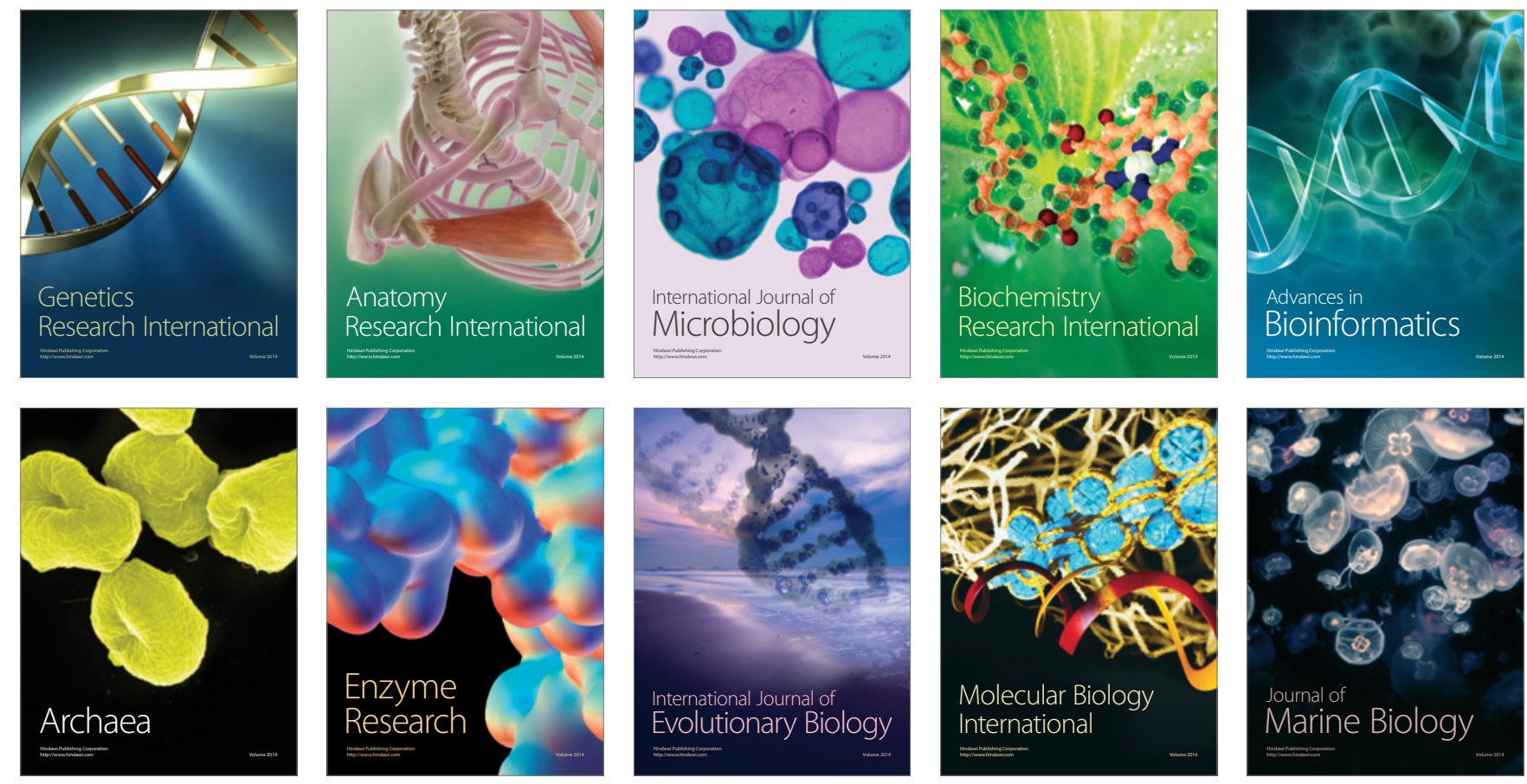